\title{
Globe
}

Revue internationale d'études québécoises

\section{Michel Biron, La Conscience du désert, Montréal, Boréal, 2010}

\section{Gilles Marcotte}

Volume 14, numéro 1, 2011

URI : https://id.erudit.org/iderudit/1005995ar

DOI : https://doi.org/10.7202/1005995ar

Aller au sommaire du numéro

Éditeur(s)

Globe, Revue internationale d'études québécoises

ISSN

1481-5869 (imprimé)

1923-8231 (numérique)

Découvrir la revue

Citer ce compte rendu

Marcotte, G. (2011). Compte rendu de [Michel Biron, La Conscience du désert, Montréal, Boréal, 2010]. Globe, 14(1), 219-222. https://doi.org/10.7202/1005995ar d'utilisation que vous pouvez consulter en ligne.

https://apropos.erudit.org/fr/usagers/politique-dutilisation/ 
Québécois n’ont jamais donné de réponse unilatérale, radicale ou sectaire. Ils ont toujours choisi de s'autonomiser dans la collaboration et de s'actualiser dans la continuation. C'est dans la tradition des tensions créatrices entre les pôles contraires, élément central de l'historicité québécoise, que les commissaires Bouchard et Taylor ont inscrit leur vision d'avenir du Québec. À défaut d'être convaincante ou enthousiasmante pour les rêveurs, cette position est sans doute sage et sensée pour la société.

Jocelyn Létourneau Université Laval

Chaire de recherche du Canada en histoire et économie politique du Québec contemporain

\section{Michel Biron}

La Conscience du désert, Montréal, Boréal, 2010.

On doit à Michel Biron deux ouvrages d'une importance certaine, tous deux marqués par la sociocritique. Le premier, La modernité belge, était issu du travail de thèse qu'il a fait en Belgique sous la direction de Jacques Dubois. Le deuxième, L'absence du maître, était consacré aux intérêts québécois. Dans les trois œuvres qu'il y étudiait, celles de Saint-Denys Garneau, Jacques Ferron et Réjean Ducharme, Michel Biron démontrait qu'elles «opèrent une rupture profonde avec les discours de leur temps, mais [que] leur geste demeure isolé, impossible à indexer sur une conscience historique ».

Il reste, dans son troisième ouvrage, La conscience du désert, le sociocritique qu'il était dans les ouvrages précédents mais, comme le titre le suggère, un peu moins soucieux de méthode que de lecture littéraire, au sens fort du mot, surtout dans les derniers chapitres. C'est que ce livre, sous-titré "Essais sur la littérature au Québec et ailleurs», est amené par sa forme même, celle d'une collection d'articles divers, français et surtout québécois, à varier les angles d'approche. Mais une question générale les réunit, qui animait déjà les réflexions du livre précédent. Citons:

Le langage de la rupture a quelque chose d'insensé et d'exorbitant pour le poète québécois (ne parlons pas du romancier ou du dramaturge, qui n'auront recours à ce langage que bien après le poète) : il affaiblit la communauté, il divise au lieu de rassembler. Sorti des rangs, le poète moderne est condamné à une solitude qui ne 
peut se confondre, me semble-t-il, avec la solitude magnifiée par le romantisme européen. Ce mot, "solitude», partout présent dans la littérature québécoise, pointe vers le vide, la folie ou l'exil.

C'est là un des thèmes les plus abondamment rabâchés de la pensée littéraire québécoise, depuis un siècle au moins, mais renouvelé ici - comme il l'était déjà dans l'ouvrage précédent - par une pensée sociale qui prend la place de la psychologique. Et ce n'est pas là une spécialité québécoise, bien que le Québec y retrouve une de ses plus anciennes tentations. "L'écrivain canadien-français, comme l'écrivain contemporain en général, écrit Michel Biron, ne se définit pas comme un écrivain de la rupture. Ou plutôt si, il voudrait bien rompre, mais avec quoi? Il n'y a personne autour de lui pour lui donner la réplique. ». Dans son ouvrage précédent, il opposait cette solitude à la rupture violente opérée dans la littérature française au début du $\mathrm{XX}^{\mathrm{e}}$ siècle. La France et le Québec retrouveraient-ils ici une parenté dans ce que l'auteur appelle une "conscience du désert"? Attendons un peu.

Dans la première partie de son nouvel ouvrage, intitulée «Le désir de culture ", Biron reprend d'abord la thèse de son livre précédent en déboulonnant le vieux cliché d'une littérature québécoise qui aurait conquis, surtout depuis la Révolution tranquille, son autonomie par rapport à la française. En fait, selon le critique, cette autonomie prétendue serait un manquement à la modernité, qui ferait de notre littérature une sorte d'arrièregarde obstinée. Le premier chapitre s'intitule "À un lecteur étranger»; il pourrait aussi bien porter le titre de "La littérature québécoise vue de loin, ou de l'étranger». Biron ne mâche pas ses mots: «L'univers, dans l'histoire littéraire québécoise, constitue un horizon redoutable. La littérature québécoise n'existe pour ainsi dire pas du tout à l'échelle de la littérature universelle. C'est regrettable (il y a de très bons écrivains ici que l'univers aimerait sans doute découvrir), mais difficilement contestable». Michel Biron n'explique pas ce malheur, comme on le fait généralement, par l'impérialisme franco-français ou même par le trop petit nombre d'œuvres québécoises aptes à franchir nos frontières. C'est la littérature québécoise en tant que telle, plus que les œuvres oserait-on dire, qui se dérobe aux exigences d'une littérature vraiment moderne. Traduisons, au risque de trahir un peu: le souci de la cohésion, qui d'ailleurs n'a pas besoin d'être explicitement affirmé, et qui permet de petits écarts mineurs, "comme une coquetterie, quand ce n'est pas une maladie ou une trahison", était avant notre temps ce qui empêchait la littérature québécoise d'exister vraiment dans le concert des littératures modernes (ou postmodernes). Biron reprendra ce thème dans un 
des chapitres ultérieurs de son ouvrage intitulé «Paris n'existe pas», qui se termine par quelques lignes sur un auteur mineur dont je ne souhaite pas parler.

Ce n'est pas exactement le nationalisme que vise ici Biron, mais une autre carence plus littérairement déterminante qui serait celle de notre littérature dans son ensemble, du début jusqu'à nos jours. Il réanime à ce propos, avec des arguments neufs, le vieux thème de la "solitude québécoise ", qui a fait les beaux (?) jours de la critique et de l'essai il y a une cinquantaine d'années. Cet attachement au thème de la solitude serait un des symptômes majeurs du refus de la modernité qui afflige la littérature québécoise. En fin de course, Biron suggère aux écrivains québécois de se doter d'une "capacité de se retirer en soi-même, d'assumer cette conscience du désert qui définit sa relation au monde». Mais n'est-ce pas cette conscience même qui l'a éloignée des grands enjeux de la littérature française et pour tout dire de la modernité?

La question se retrouvera, plus concrètement, dans les deux chapitres suivants, qui vont d'Arthur Buies - écrivain indiscutablement libéral, moderne, mais séduit en fin de course par le cher curé Labelle, apôtre de la "colonisation", rejoignant ainsi le giron de la fidélité nationale -, à des écrivains modernes très divers, dont Jacques Godbout, Roland Giguère et Louis Hamelin. C'est là un autre plongeon dans le négatif: "La figure de l'autodidacte, à l'époque contemporaine, constitue une anomalie, une fantaisie, un anachronisme, un retour aux valeurs archaïques». La littérature québécoise serait-elle donc renvoyée ainsi à l'arrière-garde, comme elle l'était dans le chapitre précédent par l'idée de solitude?

Le ton change dans la deuxième partie du livre, ne serait-ce que par la juxtaposition, plus ou moins arbitraire en apparence, d'œuvres très diverses, québécoises bien sûr, mais aussi françaises et américaines. Voici réunis, par d'étonnantes rencontres plus ou moins planifiées, Louis Hémon - il y a ici une relecture tout à fait neuve et forte de Maria Chapdelaine -, Houellebecq, Ducharme, Suzanne Jacob, Mallarmé, Marie-Claire Blais et des comparses comme le Belge Jean-Philippe Toussaint, l'Américain Philip Roth et le Sud-Africain J.-.M. Coetzee. Est-ce dire que ces rapprochements relèvent seulement du hasard des demandes universitaires? Oui, et non. Le Michel Biron des deux dernières parties du livre reste lui-même et ne peut s'empêcher de poursuivre de façon plus ou moins ostensible les interrogations de la première. Mais il les module d'une façon nouvelle. Louis Hémon fait surgir dans le débat une "tentation du désert» qui a des échos chez le Houellebecq d'Extension du domaine de la lutte, et nous parle d' "un 
monde non conflictuel [où] le personnage n'a d'autre choix que de prendre congé». Et voici - on ne l'attendait pas là - parlant d'un "vide en train de se faire», Suzanne Jacob qui fait dire à son personnage Delphine: «Le futur expire», «le futur est $\mathrm{KO}$ ».

«Évitons les conflits», c'est le titre d'un chapitre où l'on rencontre, entre autres, l'Américain Roth et le Sud-Africain Coetzee. Témoigneraient en ce sens l'adieu au roman d'André Major, La vie provisoire, de même que le roman de Pierre Nepveu, Des mondes peu habités (le titre parle clairement), qui «imagine[nt] un monde de l'après-rupture: les événements majeurs ont déjà eu lieu». Enfin, dans le roman de Marie-Claire Blais, Soifs, pourquoi les personnages ne se logent-ils pas dans la mémoire du lecteur? «Il est bien sûr possible de se faire une liste des personnages du roman, mais c'est là un exercice assez fastidieux...» Continuons : «l'intrigue est à peu près nulle, le temps semble suspendu...». Est-ce encore un roman que nous lisons là?

Michel Biron semble suggérer, en faisant se rencontrer ainsi des romans québécois et étrangers, surtout français, que les intérêts des premiers se rapprochent enfin des seconds. Ce n'est pas dire que nos écrivains d'aujourd'hui seraient supérieurs à ceux qui les ont précédés, mais qu'ils sont pour ainsi happés par une nouvelle modernité, planétaire celle-là. La forme des derniers chapitres du livre, réunissant des textes divers, souvent très différents les uns des autres, pourrait nous faire douter de la cohérence globale de l'ouvrage. Mais les rencontres assez étonnantes que Biron organise entre romans québécois et romans occidentaux, particulièrement celui de Houellebecq, nous renvoient à "un monde non conflictuel», dont il dresse fortement l'image. Le roman change, nous dit le sociocritique, parce que la société change. Et ce changement serait perceptible aussi bien, et peut-être de la même façon, au Québec que dans le reste du monde occidental.

Il faut donc dire, avec insistance, que malgré les apparences, $L a$ Conscience $d u$ désert n'est pas un simple ramassis de textes divers. Il y a là une pensée chercheuse qui prend plus de risques que dans les ouvrages précédents, et par là peut sembler moins sûre, mais qui nous invite à mettre en question les schémas des premiers chapitres. La forme éclatée de l'ouvrage, ou son manque de forme si l'on veut, permet à Michel Biron d'ouvrir des perspectives parfois discutables, mais par là même intéressantes, fécondes. Il y a du neuf dans ce livre.

Gilles Marcotte

Université de Montréal 